\title{
Risk assessment of genetically engineered plants that can persist and propagate in the environment
}

\author{
Andreas Bauer-Panskus ${ }^{1}$, Juliana Miyazaki ${ }^{1}$, Katharina Kawall ${ }^{2}$ and Christoph Then ${ }^{1 *}$
}

\begin{abstract}
New challenges arise in risk assessment when genetically engineered (GE) plants can persist and propagate in the environment as well as produce viable offspring. Next generation effects can be influenced by heterogeneous genetic backgrounds and unexpected effects can be triggered in interaction with environmental conditions. Consequently, the biological characteristics of the original events cannot be regarded as sufficient to conclude on hazards that may emerge in following generations. Potential hazards identified by the European Food Safety Authority (EFSA) include exacerbating weed problems, displacement and even extinction of native plant species. However, there are reasons for concern that might escape the environmental risk assessment (ERA) because EFSA only takes into account the characteristics of the original events, leaving aside unintended or unexpected next generation effects emerging from spontaneous propagation and gene flow. From our review of the publications available and the analysis of risk assessment as performed, we conclude that the risk assessment of GE organisms able to persist and spontaneously propagate in the environment actually suffers from a high degree of spatio-temporal complexity causing many uncertainties. To deal with this problem, we recommend establishing 'cut-off criteria' in risk assessment that include factual limits of knowledge. It is proposed that these criteria are applied in a specific step within risk assessment, i.e. 'spatio-temporal controllability' that uses well-defined biological characteristics to delineate some of the boundaries between known and unknowns. This additional step in risk assessment will foster robustness in the process and can substantially benefit the reliability and overall conclusiveness of risk assessment and decision-making on potential releases.
\end{abstract}

Keywords: Genetically engineered plants, Environmental risk assessment, Long-term effects, Next generation effects, Spatio-temporal control, Cut-off criteria, GMO regulation

\section{Background}

Human influence in agriculture and land use has led to plants and animals being selected and cross-bred over thousands of years to establish beneficial and desirable traits. The processes enrolled in conventional breeding are mostly based on mechanisms that have developed during evolution and are not targeted. The period of time required to generate new plant varieties with the desired

\footnotetext{
*Correspondence: christoph.then@testbiotech.org

${ }^{1}$ Testbiotech e.V, Institute for Independent Impact Assessment

of Biotechnology, Frohschammerstr. 14, 80807 Munich, Germany

Full list of author information is available at the end of the article
}

characteristics from crossing and selection enables various feedback mechanisms to check and sustain functionality. All in all, conventional breeding mostly builds on gradual changes in contrast to genetic rearrangements and abrupt/disruptive additions of additional DNA coding for novel proteins or drastic metabolic changes.

Genetic engineering enables natural mechanisms developed during the process of evolution to be changed in more depth or, to some extent, circumvented [1]. Consequently, experience gained from conventional breeding cannot simply be extrapolated to the risk assessment of genetically engineered (GE) organisms. Directive 
2001/18/EC [2] requests that all organisms derived from processes of genetic engineering require a risk assessment before they can be released.

The precautionary principle (PP) plays a crucial role in EU regulation and is essential in making decisions on the risks of genetically engineered organisms. It is one of the fundamental principles on which EU policy is based in regard to the environment as well as health and food safety [3]. The PP was formally adopted in the Maastricht Treaty in 1992 and is enshrined in Article 191(2) [4] of the Treaty on the Functioning of the European Union, it has been incorporated into a number of measures of secondary legislation (Regulations and Directives) which apply to member states. The main feature of the PP is the prevention of risks in the face of scientific uncertainty, aiming to avoid harm before a hazard manifests. More detailed descriptions of the PP and its application in the EU can be found elsewhere $[5,6]$. In this context, it is important that the PP is of fundamental significance for GMO Regulation in the EU (Article 1 of Directive 2001/18/EC [2]).

According to the European Food Safety Authority (EFSA), there are specific hazards which have to be assessed in the risk assessment of GE plants in regard to "Persistence and invasiveness including plant-to-plant gene flow" [7]. All of them deal with a change in fitness: "The potential adverse effects are of two main types. First, enhanced fitness of the GM plant or of transgenic (introgressed) wild relatives within production systems may make them more persistent, exacerbating weed problems that may need to be controlled by more complex weed control strategies, which themselves might cause environmental harm. Second, enhanced fitness of transgenic feral plants, or of transgenic (introgressed) wild relatives in semi-natural or natural habitats may reduce the diversity/abundance of valued flora and fauna. For instance, native plant species may be displaced, which in turn might affect species that use those plants as food, shelter, etc. Alternatively, and depending on which plant and which transgenes are involved, gene flow to wild relatives may decrease the fitness of hybrid offspring. If rates of gene flow are high, this may cause wild relatives to decline locally, or to become extinct (e.g. swarm effect, outbreeding depression)" [7].

This review investigates the question of how changes in the fitness of volunteer offspring and hybrids of GE plants can be assessed. More generally, we explore whether risk assessment as established by EFSA [7] is sufficient to identify all relevant hazards that might emerge from the persistence and spread of GE plants in the environment. In this context, we discuss to which extent persistence and spontaneous propagation of GE plants as well as potential gene flow to wild relative species have to undergo detailed risk assessment, including cases where it is not yet known whether the offspring will actually show enhanced fitness.

Further, we present an overview of biological characteristics with relevance for the Environmental Risk Assessment (ERA) of GE plants in this context. We summarise specific challenges associated with the ERA of GE plants that can persist and propagate in the environment; also identifying relevant gaps in EFSA risk assessment and presenting case studies. Finally, we outline some of our conclusions and specific regulatory recommendations.

\section{Changes in fitness and ERA of GE plants}

Changes in fitness are highly relevant in the context of ERA of GE plants that can persist and spontaneously propagate in the environment, e.g. oilseed rape (Brassica rapa) or Camelina (Camelina sativa). Such changes may cause the plants to become invasive, or able to alter ecosystem structures, or disrupt ecosystem processes [7]. Fitness is a term used in evolutionary biology (see, for example, [8]). The fitness of individuals of a sexually propagating species can be determined by comparing their reproductive success. If the reproductive success of an individual is higher than the rest of the population, this can be called enhanced fitness. In general, fitness is dependent on the genotype and the environment: some individuals might be better suited to survive under specific environmental conditions than others. In this context, we propose differentiating between potential changes in the fitness of GE plants that are intended and expected, or unintended but can be expected, or unintended and unexpected. While the first two categories emerge from the trait, the last one involves further genomic effects or interactions between the genotype and the environment.

\section{Changes in fitness emerging from the trait}

Enhanced fitness can be intended via the trait. While many approaches to intentionally increasing fitness have been discussed [9-12], so far only a few have been realised in commercial cultivation, e.g. a GE maize plant cultivated in the US, which is claimed to be drought-tolerant [13].

Enhanced fitness can also be associated with the trait without this being intended. Traits intended to enhance production by introducing herbicide resistance, insecticidal properties or tolerance to biotic stressors, such as viruses, can also confer enhanced fitness under specific environmental conditions. For example, herbicide-resistant GE plants have been shown to have a higher survival rate and therefore established in parts of the environment, such as ruderal areas (waste ground) or transport routes where the complementary herbicide is being used 
for weed control $[14,15]$. If the herbicide to which the GE plants are resistant is used frequently, e.g. as with glyphosate, this can become an issue for risk assessment. Furthermore, if plants that have been engineered to be tolerant to biotic stressors, such as pest insects or viruses, are established in the environment, the GE plants will show a higher survival rate if exposed to these stressors. For example, GE rice showed a higher fitness in experiments where the plants were under insect pest pressure [16]. If introgressed into wild relatives, the offspring can benefit from the trait [17-23]. Similar observations were made with virus resistance in squash [24] and radish [25].

Furthermore, changes in the fitness of GE plants can emerge unintentionally and unexpectedly from genetic backgrounds or might be triggered by specific environmental conditions. The causes of unintended changes in fitness are associated with uncertainties that may be challenging for ERA and are, therefore, reviewed in more detail in the following paragraphs.

\section{Unintended changes in fitness emerging from genomic effects}

The process of genetic engineering may result in lower fitness of the plants compared to their isogenic comparator. It is known that reduced fitness can also result from conventional breeding; in many cases domesticated plants show lower fitness compared to their wild relatives [26]. However, by escaping natural processes, such as gene regulation or heredity, the causes and consequences of lowered fitness in GE plants may differ. For example, when a metabolic pathway is introduced into a plant rather than developed and adapted over time in a certain environment, this might imply some fitness costs. For example, Huang et al. [27] reported a tendency to lower fitness in some rice hybrids stemming from transgenic plants producing $\mathrm{Bt}$ toxins.

In other cases, lower fitness is caused by unintended effects such as interruption of endogenous genes. For example, after crossing lines of "Golden Rice" with the Indian variety, Swarna, Bollinedi et al. [28] observed a growth disturbance since the gene constructs encoding traits for increased production of precursors for vitamin A interfered with the plant's own gene for producing growth hormones. The integration of the transgene disrupted the native OsAux1 gene, which encodes an auxin transmembrane transporter protein, therefore most likely interfering with the fine-tuning of plant growth regulators auxin, gibberellic acid and abscisic acid. The gene constructs were not, as intended, active solely in the kernels but also in the leaves [28]. This caused a substantial reduction in the chlorophyll content in the leaves, leading to pale green leaves in homozygous plants. This effect was not observed in other varieties, showing the possible impact of the genetic background on the phenotype. Such metabolic disruptions typically do not occur with conventional breeding, which brings about gradual changes in contrast to genetic rearrangements and abrupt/disruptive additions of additional DNA coding for novel proteins and drastic metabolic changes, which were explained by Wilson [29], who coined it 'metabolic meltdown'

The process of genetic engineering can also unintentionally enhance the fitness of the relevant plants. For example, the amounts of pollen and seeds or responses to environmental stress conditions might be changed. There is evidence that these effects occur due to the transformation process of genetic engineering: Fang et al. [30] showed that higher fitness does occur in GE glyphosate-resistant Arabidopsis thaliana in a glyphosate-free environment. According to this research, the expressed enzyme EPSPS (5-enolpyruvylshikimate-3-phosphate synthase) not only makes the plants resistant to glyphosate, it also interferes with metabolic processes associated with their growth and fecundity. As a consequence, plant offspring can produce more seeds and be more resistant (tolerant) to environmental stressors such as drought and heat. The authors stated that the observed effects are likely to be caused by increased production of the hormone auxin in the transgenic plants. This plant hormone plays a key role in growth, fecundity and adaptation to environmental stressors. The general findings regarding enhanced fitness of plants inheriting additional EPSPS genes [30] are supported by several other publications [31-34], while other authors show the need for further investigations [35,36], report unchanged fitness [37] or even high fitness costs in certain weeds [38].

There are other cases where higher fitness emerges from position effects depending on the insertion site of the additional DNA. For example, in its patent application WO 2004053055 [39], Monsanto claims transgenic plants emerging from the process of transformation "producing unexpected but yet desired phenotypes". As described in the patent: "One aspect of the invention provides transgenic maize seed for maize line which exhibits enhanced yield as compared to yield for parental maize line, in another aspect the invention provides transgenic maize seed for a maize line characterized by enhanced yield under stress conditions. In another aspect the invention provides transgenic maize seed for maize lines characterized by other enhanced traits, e.g. an enhanced quality in plant morphology, plant physiology or seed component phenotype as compared to a corresponding phenotype of a parental maize line."

There are also publications showing enhanced fitness occurring from the introgression of GE plants into genetic backgrounds of other varieties or relatives. It 
is likely that these next generation effects will emerge from heterogeneous genetic backgrounds and effects of hybridisation (see, for example, [27]). In the following section, we provide a tabled overview of changed fitness due to unexpected effects occurring with the process of genetic engineering (Tables 1,2). We use two plant species as examples, rice and oilseed rape.

Rice was chosen because of possible hybridisation with wild relatives. Rice provides a useful example here since it has a history of double domestication (or re-domestication) with periods in between of "dedomestication", or reversion to a wild form [40, 41]. Consequently, gene flow between wild and cultivated rice forms growing close by (weedy rice) is extensive [2]. The gene flow between fields and weedy rice can also be circular and repetitive [43]. Table 1 gives an overview of unexpected effects that impact fitness in rice after GE plants are introgressed into other genetic backgrounds.
Transgenic oilseed rape is known to be established independently from cultivation in several regions of the world such as Canada, the US, Japan, Australia and Switzerland (for overview see, for example, [49] and more recently in Argentina [50]). In some countries, such as Canada and Japan, it has to be assumed that there has already been some gene flow of transgenes into populations of wild relatives. Apart from commercial cultivation (such as that in Canada and the US) and experimental field trials, the import, transport and associated spillage of viable grains for food and feed production (such as in EU and Japan) are the main source of uncontrolled dispersal of these plants. This is also the case in Switzerland, where evidence has been found that GE oilseed rape established populations and outcrossed into non-GE oilseed rape [51]. Interestingly, some populations seem to be self-sustaining and can persist without additional gene flow (spillage) at Japanese harbours [52, 53]. Similar findings are also reported from Canada $[54,55]$. This

Table 1 Unexpected effects that impact fitness in rice after GE plants are crossed into genetic backgrounds of weedy or cultivated rice

\begin{tabular}{|c|c|c|}
\hline Trait & Findings & References \\
\hline Insecticidal & $\begin{array}{l}\text { Enhanced relative performance of the crop-weed hybrids, taller plants, more tillers, panicles, and spikelets per plant, } \\
\text { as well as higher } 1000 \text {-seed weight, compared with the weedy rice parents } \\
\text { Seeds from the F1 hybrids had higher germination rates and produced more seedlings than the weedy parents }\end{array}$ & [44] \\
\hline Herbicide tolerance & $\begin{array}{l}\text { Transgenic F2 crop-weed hybrids produced } 48-125 \% \text { more seeds per plant than non-transgenic controls } \\
\text { Transgenic hybrids also had higher EPSPS protein levels, tryptophan concentrations, photosynthetic rates, and per } \\
\text { cent seed germination compared with non-transgenic controls } \\
\text { Findings suggest that overexpression of a native rice EPSPS gene can lead to fitness advantages, even without } \\
\text { exposure to glyphosate }\end{array}$ & [33] \\
\hline Insecticidal & $\begin{array}{l}\text { Transgenes can significantly alter the segregation distortion pattern in hybrid progeny, particularly the direction of } \\
\text { segregation deviated according to different parents. Transgenes with strong selection advantages may have evo- } \\
\text { lutionary impacts on hybrid progeny by changing their pattern of allelic segregation distortion after introgression } \\
\text { from transgenic crops to wild relatives through hybridisation }\end{array}$ & [45] \\
\hline Insecticidal & Weedy rice has increased fitness after the introgression of Bacillus thuringiensis (Bt) genes from cultivated rice & [17] \\
\hline Insecticidal & Increase of Bt content in some hybrids of wild rice and cultivated rice & [46] \\
\hline Insecticidal & Lower insect damage and higher fecundity in hybrids & [47] \\
\hline Herbicide tolerance & $\begin{array}{l}\text { Transgenic hybrid lineages showed significantly earlier tillering and flowering, as well as increased fecundity and } \\
\text { overwintering survival/regeneration abilities }\end{array}$ & [34] \\
\hline Herbicide tolerance & $\begin{array}{l}\text { Fitness of feral progeny was significantly higher after introgression from weedy rice to glufosinate-resistant trans- } \\
\text { genic hybrid rice }\end{array}$ & [48] \\
\hline $\begin{array}{l}\text { Herbicide tolerance } \\
\text { and insecticidal }\end{array}$ & $\begin{array}{l}\text { Fitness of progeny in cultivated rice and weedy rice was found to depend on the environment, selective pressure } \\
\text { and genetic background }\end{array}$ & [27] \\
\hline
\end{tabular}

Table 2 Unexpected effects that impact fitness in Brassica rapa after GE oilseed rape is crossed into other genetic backgrounds or which unexpectedly emerged in persisting transgenic populations

\begin{tabular}{ll}
\hline Trait & Findings \\
\hline $\begin{array}{l}\text { Insecticidal } \\
\text { Berbicide tolerance }\end{array}$ & $\begin{array}{l}\text { The properties of some feral transgenic oilseed rape plants seem to have changed, e.g. by showing higher growth } \\
\text { and becoming perennial. Climate conditions may be an impact factor for these effects }\end{array}$ \\
[57] & $\begin{array}{l}\text { Populations of transgenic plants can persist in the environment without additional gene flow or factors for specific } \\
\text { selection }\end{array}$ \\
\hline
\end{tabular}


is a strong indication that the fitness of these transgenic plants was underestimated. One possible explanation for the higher fitness of transgenic, glyphosate-resistant oilseed rape are the findings from Fang et al. [30], which show that enhanced fitness is triggered by the EPSPS enzyme, including in a glyphosate-free environment. Fang et al. [30] performed their experiments with Arabidopsis thaliana which belongs to the same plant family (Brassicaceae) as Brassica rapa. Therefore, it can be assumed there is some likelihood of similar biological effects occurring in both species, although further research is needed to confirm this assumption (see also [36]). Table 2 gives an overview of unexpected effects in oilseed rape that impact fitness after GE plants are introgressed into other genetic backgrounds, or which unexpectedly emerged in persisting transgenic populations.

It should be noted that some of these effects might emerge mostly in the first generation due to the effects of hybridisation. As a result, these effects might not be, or might only partially be, inherited in the following generations. Nevertheless, they are relevant in this context since these effects might occur reiteratively and also become cumulative.

\section{Changes in fitness can be triggered}

\section{by genome $x$ environmental interactions}

It is well known that unintended effects in GE plants can be triggered by changing environmental conditions or biotic and abiotic stressors [30, 58-63]. There are several reasons why GE plants show unexpected effects in their interaction with the environment. Specific attention should be paid to the genetic functional stability of the inserted DNA. Unlike other organisms, GE crops inherit technically altered DNA in their cells that do not emerge from evolutionary mechanisms. Many gene constructs are composed of multiple elements, such as promoters and stop codons derived from different organisms, e.g. viruses, bacteria, plants, etc., which do not have a (evolutionary) history in the engineered GE crops. These gene constructs can escape the natural gene regulation of plant cells. Under the conditions of climate change or in interaction with other stress factors and combined with various genetic backgrounds, unexpected effects can emerge in the GE crops that pose risks for the environment and ecosystems.

As mentioned, Fang et al. [30] showed that higher fitness does occur in GE glyphosate-resistant plants in a glyphosate-free environment. They also describe how environmental stressors such as heat and drought can enhance these effects: in transgenic Arabidopsis events producing one of three additional transgenic EPSPS enzymes, they observed significantly increased seed germination ratios when transgenic seeds were exposed to heat and drought stresses, although no differences were found in seed germination among different lines when seeds were exposed to normal temperatures. They discuss that this effect is caused at the protein level by interference of the EPSPS enzyme with the auxin metabolism which can promote seed germination and plant growth under abiotic stresses.

In addition, several studies with GE plants such as petunia, cotton, potato, soybean and wheat have reported unexpected reactions to environmental stress conditions (Table 3). Some of these effects might enhance fitness:

\section{Table 3 Examples of unexpected effects in GE plants due to genome x environmental interactions}

\begin{tabular}{|c|c|c|c|}
\hline Plant & Trait & Findings & References \\
\hline Wheat & Resistance against the fungus powdery mildew & $\begin{array}{l}\text { In a field experiment two of four GE lines showed up to 56\% yield } \\
\text { reduction and a } 40 \text {-fold increase of infection with ergot disease } \\
\text { Claviceps purpurea compared with control lines. These effects were } \\
\text { not observed in greenhouse experiments }\end{array}$ & {$[62]$} \\
\hline Oilseed rape & Herbicide tolerance & Perennial growth & {$[57]$} \\
\hline Maize & Insecticidal & $\begin{array}{l}\text { Changes in proteome ( } 32 \text { differentially expressed proteins mainly } \\
\text { involved in carbohydrate and energy metabolism and stress } \\
\text { response) }\end{array}$ & {$[64]$} \\
\hline Potato & $\begin{array}{l}\text { Several experimental traits (antisense invertase } \\
\text { and maize ribosome-inactivating proteins) }\end{array}$ & $\begin{array}{l}\text { Altered levels of metabolites (sesquiterpenes and glycoalkaloids) in } \\
\text { response to biotic stress }\end{array}$ & {$[58]$} \\
\hline Petunia & Colour of flowers & Altered DNA methylation in $35 \mathrm{~S}$ promoter of the A1 gene & {$[59]$} \\
\hline Maize & Insecticidal & $\begin{array}{l}\text { Bt content higher or lower due to environmental impact factors such } \\
\text { as fertilizer, soil quality, pesticide application and climate }\end{array}$ & {$[60]$} \\
\hline Maize & Insecticidal & $\begin{array}{l}\text { Environmental stress can cause unexpected patterns of expression in } \\
\text { the newly introduced DNA }\end{array}$ & {$[61]$} \\
\hline Arabidopsis & Herbicide tolerance & Drought and heat stress caused increased seed germination ratios & {$[30]$} \\
\hline Cotton & Insecticidal & $\begin{array}{l}\text { Bt content is influenced by environmental conditions and genetic } \\
\text { backgrounds }\end{array}$ & {$[42,63,65-70]$} \\
\hline
\end{tabular}


for example, there are several findings showing that the Bt content in the plants is influenced by environmental conditions (Table 3).

In addition, specific environmental conditions, such as high pressure from pest insects or spraying with the complementary herbicides, can also become a significant driver for enhancing the fitness of the plants and their potential offspring.

The complexity in risk assessment can be exemplified with GE rice: if GE rice showing tolerance to biotic or abiotic stress factors can pass its characteristics on to weedy rice, several levels of complexity have to be taken in account for the offspring and hybrids of these plants:

(i) Gene flow between the domesticated and the weedy rice can trigger enhanced fitness (or other biological characteristics) in next generations even if no such characteristics were observed in the original events. Gene flow introduced the added genetic material into various genetic backgrounds which can cause unintended effects, especially in hybrids (Table 1). (ii) If gene flow occurs as described for weedy and domesticated rice $[40,41]$, new combinations of genetic material can occur in following generations, such as spontaneous stacked transgenic events with, e.g. resistance to several biotic or abiotic stressors. These combinations can trigger enhanced fitness or other biological effects with much stronger impacts than observed in the original event or early hybrids. (iii) Finally, if the plants persist over a longer period of time and/or spread to various receiving environments, the likelihood that enhanced fitness or other biological effects are triggered by environmental $\times$ genome interaction (Table 3 ) may increase. Relevant effects might be absent in the first generation(s) and only emerge after several crossings and/or under specific environmental circumstances.

For example, Huang et al. [27] examined the next generation effects of stacked rice producing Bt toxins and made tolerant to glufosinate. Indications for lower and higher fitness were found, depending on selective pressure and the genetic background. They explicitly mention the need to investigate these effects over several generations.

As shown, if GE plants can persist in the environment and/or if gene flow with domesticated and/or wild relative plants can be established and lead to viable offspring, the resulting offspring might show unintended changes regarding their fitness that cannot be predicted from the data of the original events. These observations are in line with previous publications which show that the impact of gene flow and interactions with genetic backgrounds and the environment should be assessed thoroughly $[30,32,71]$. As a result, it is evident that new challenges arise in risk assessment when GE plants can persist and propagate in the environment as well as produce viable offspring.

\section{Other effects and interactions of relevance for risk assessment of GE plants that can persist and propagate in the environment}

Changes in fitness of the GE crop plants are considered by EFSA to be the only and the most relevant issue when it comes to risk assessment of "persistence and invasiveness including plant-to-plant gene flow". However, this is not the only problem that might arise from persistence and self-propagation of GE crops in the environment. In the following section we give three examples to illustrate other relevant issues:

1. Bt-producing plants such as cotton [72] or poplar trees [73] are examples of GE plants that can persist and propagate in the environment [49]. These plants are likely to show higher fitness compared to their wild relatives under selection pressure from Btsusceptible insects feeding from the plants. However, beyond changes in fitness, there are other risks that need to be considered such as long-term exposure of ecosystems to Bt toxins produced by the GE plants: the Bt toxins will not only be taken up by insects feeding from these plants or be secreted via roots [74] and change a plant's rhizosphere [75], but Bt containing plant material such as pollen, seeds, leaves and roots can be distributed in the wider environment. While in the short-term Bt toxins can cause developmental impairments and behavioural changes [76, 77], large-scale and long-term exposure might cause a substantial increase in these effects, cause changes in insect populations and disturb the functions of the associated ecosystems. The problems in assessing long-term effects are reflected in research by Stewart et al. [78] and Andow and Zwahlen [79], who refer to the potential impact of the intended traits if transferred into wild populations. It should be taken into account that the Bt content in the plant material can also be influenced by environmental conditions or heterogeneous genetic backgrounds in the offspring [61].

2. Life forms interact with the environment via multiple bio-chemical pathways. In plants, this includes signalling and 'communication' with other plants, microorganisms and insects [80, 81]. There are various compounds involved such as volatile substances, other secondary metabolites and biologically active compounds. The interactions with the environment encompass the closer (associated microbiomes) or wider environments (such as food webs, predators, beneficial organisms, other plants). 
Natural processes, such as gene regulation and heredity, can be circumvented with modern genetic engineering tools (e.g. transgenesis and genome editing), and experience shows that interactions with the environment known from conventional plant breeding cannot simply be extrapolated to GE plants. For example, da Silva et al. [82] and Wallace et al. [83] show differences in the associated microbiomes of transgenic plants are not only influenced by the environment but to some extent also impacted by plant genetics. Therefore, ERA of GE organisms should include potential (intended and unintended) changes of these signalling pathways since they can substantially disturb or even disrupt the functions of the ecosystems.

These risks are especially relevant if genetic engineering changes endogenous metabolic pathways to make plants, e.g. more resistant to stress conditions or to increase their yield. The metabolism underlying plant growth, stress resistance or plant composition is very often multifunctional and complex. Under these circumstances, any risk assessment has to be driven by the hypothesis that the biological characteristics of the plants are systematically changed by the genomic intervention (e.g. transgenesis or genome editing), including signalling with the wider or closer environment.

3. Changes in plant composition causing an altered nutritional quality can result in specific disturbances in the ecological systems via the associated food webs. Since plant composition can be altered by methods of genetic engineering to a much greater extent compared to conventional breeding, existing experience cannot simply be extrapolated to GE plants (derived from transgenesis or genome editing). Therefore, ERA of GE organisms should include potential (intended and unintended) changes of plant composition and their effects on the ecosystems. For example, Colombo et al. [84] indicate potential hazards for food webs that result from the extensive cultivation of GE plants such as oilseed rape producing the long-chain omega-3 fatty acids eicosapentaenoic acid (EPA) and docosahexaenoic acid (DHA), which are not generally produced by terrestrial plants. In other words, novel plant components with no putative evolutionary precedents may enter ecosystems and cause complex risks: the omega- 3 fatty acids in the plants can, for instance, change the growth and fecundity of the organisms that feed on them because they are not normally present in terrestrial diets. If such GE oilseed rape were to be grown in Europe, relevant characteristics might be spread by gene flow to other domesticated or wild populations, and resulting effects could be carried forward into the food chain [84].

The examples above show that plants able to persist and spontaneously propagate in the environment pose substantial challenges for risk assessment, even when the fitness of the plants is not changed.

\section{Specific challenges for risk assessment going along with long-term and next generation effects}

From the findings regarding next generation effects presented above, it can be concluded that the ERA of GE plants, i.e. their robustness, reliability and overall conclusiveness will be decisively influenced by questions of whether the plants can persist in the environment, whether they can spontaneously propagate and/or if gene flow with domesticated and/or wild relative plants can be established leading to viable offspring either in agricultural or semi-natural and natural habitats. The answers given to these questions will substantially impact problem formulation, hazard identification and characterisation, as well as exposure characterisation and final risk characterisation. Generally, if GE plants can persist in the environment and/or if gene flow with domesticated and/ or wild relative plants can be established leading to viable offspring, the uncertainties will increase and risk assessment will face more complex questions than is the case with plants that cannot persist and cannot establish gene flow.

It makes a fundamental difference for the risk assessment, if GE plants are grown for just one season in the fields or if they are produced for several consecutive years. In the first case companies may check the seeds every year in regard to their biological or economic characteristics. However, in the second case, GE offspring or potential hybrids can develop which do not undergo additional quality or safety checks before they appear in the fields. This is especially relevant in cases where selfsustaining populations of GE plants become established, regardless of whether they are established within the production systems or beyond.

Thus, if the plants can persist in the environment and/ or if gene flow with domesticated and/or wild relative plants can be established, leading to viable offspring, then hazard identification and characterisation has to include several and complex scenarios, including those dealing with hazards that are not predictable from the data of the original events.

Potential harm can be caused by enhanced weediness, invasiveness and disruption of ecological networks. Relevant causes and scenarios have to take into account genome $\times$ environment interactions, next generation effects emerging from heterogeneous genetic 
backgrounds, epigenetic effects and effects of hybridisation with wild relatives. These effects do not depend on specific scenarios for distribution into the environment such as introgression into wild populations or spreading beyond sites of agricultural production: it is, for example, sufficient if the transgenes persist and spread in regional varieties of maize in Mexico, which is one of the countries of origin [85]; any of the effects mentioned above are relevant for overall risk analysis.

The same is true for potential gene flow from and to teosinte observed in the fields in Spain [86]: these plants are wild relatives (ancestors) of cultivated maize. Depending on the subspecies of teosinte, gene flow is more or less likely to occur. The subspecies occurring in Spain has not been fully identified and seems to be a hybrid between maize and teosinte.

In 2016, EFSA [87] reviewed the risks of gene flow from GE maize producing Bt toxins and made resistant to glyphosate (MON810, Bt11, Maize 1507 and GA21) to teosinte plants occurring in Spain and France.

The opinion of the EFSA GMO Panel [87] is based on data extrapolated from teosinte in Mexico, assuming that the teosinte in Spain is very similar. However, Trtikova et al. [86] showed major differences between the genetics of teosinte stemming from Mexico and Spain. Thus, the real potential for gene flow for teosinte growing in Spain cannot be assessed by simply extrapolating the data from Mexico. Furthermore, EFSA assumes that-if gene flow occurs-the biological characteristics in the hybrid offspring are predictable from the original maize events. However, being aware of the large differences in the genomic background of cultivated maize and the species of teosinte, this hypothesis does not seem to be plausible. Rather, it has to be assumed that the integration of the transgenes into teosinte would result in plants that have to be regarded as an independent event and assessed accordingly.

However, these uncertainties, unknowns and resulting risks remained unconsidered in the EFSA opinion. Even though expression data for transgenes in hybrid offspring were completely lacking, it was assumed that any hybrids would, at most, express the traits of the transgenes known from the original events [87-89]. As shown above, this might well be wrong. Since the effects caused by gene flow largely depend on interactions with the environment and the genetic backgrounds of the plants, the characteristics of volunteer offspring and next generation effects may not be predictable from the characteristics of the original event.

This increasing complexity is not only a problem for ERA in the EU. It is a global issue especially for plant species that readily persist in the environment and/ or spread into domesticated or native relatives. Several plant species used in genetic engineering, such as alfalfa, creeping bentgrass, cotton, eggplant, maize, oilseed rape, poplar and rice, are known for their potential to persist and for gene flow in the regions where they are cultivated $[49,89]$. As a recent report of the International Union for Conservation of Nature [90] shows, there are several projects working on GE insects, corals, amphibians, rodents or trees that might be introduced into natural populations. While the reported purpose of these projects is nature conservation, it seems that the long-term consequences for biodiversity were hardly considered at all [91].

\section{The problem of spatio-temporal complexity and current ERA practice}

In its guidance documents for the ERA of GE organisms of 2010 [7] EFSA foresees that each event has to be assessed case-by-case and step-by-step, and EFSA identifies seven specific areas of concern that should be addressed: (1) persistence and invasiveness of the GE plant, or its compatible relatives, including plant-to-plant gene transfer; (2) plant-to-microorganism gene transfer; (3) interaction of the GE plant with target organisms; (4) interaction of the GE plant with non-target organisms; (5) impact of the specific cultivation, management and harvesting techniques, including consideration of the production systems and the receiving environment(s); (6) effects on biogeochemical processes and (7) effects on human and animal health.

However, within the staged approach as suggested by EFSA [7] for assessing persistence and invasiveness, the potential impacts caused by GE plant offspring are mostly addressed at the level of the original event only.

This becomes clear from the aforementioned EFSA opinion on gene flow from some Bt maize events in Spain and France [87] to teosinte and by the way in which EFSA dealt with a case of potential spillage from the transport of viable kernels of GE oilseed rape MON88302 described below. This herbicide-resistant GE crop was developed by Monsanto to withstand even higher dosages and even more frequent applications of glyphosate than before [92]. It was assessed by EFSA [92] and is allowed for import into the EU.

Environmental risk assessment as set out in EFSA guidance [7] requires that spillage from viable kernels of imported products is also assessed: "It should also consider viable GM plant seeds or propagules spilled during import, transportation, storage, handling and processing that can lead to feral plants that colonize and invade ruderal, semi-natural and natural habitats." EFSA [93] was of the opinion that the import and transport of MON88302 (which they summarised as genetically modified herbicide tolerant-GMHT-oilseed 
rape), is indeed likely to establish volunteer plants along transport routes and at processing facilities: "The EFSA GMO Panel confirms that feral GMHT oilseed rape plants are likely to occur wherever GMHT oilseed rape is transported." EFSA did not consider this to be a problem: "However, there is no evidence that the herbicide tolerance trait results in enhanced fitness, persistence or invasiveness of oilseed rape MON 88302, or hybridising wild relatives, unless these plants are exposed to glyphosate-based herbicides. Escaped oilseed rape plants and genes introgressed into other cross-compatible plants would therefore not create any additional agronomic or environmental impacts."

As mentioned above, several publications show that spillage from transport can occur in amounts that give rise to populations that can persist in the environment over several years, and also that gene flow occurs between these populations and wild relatives [49, 5153]. Not only under selection pressure (for example, glyphosate treatment for glyphosate-tolerant oilseed rape) but also without it, these populations can grow in number and contribute to gene flows in neighbouring fields [94].

One possible reason for this is that the EPSPS enzyme which confers resistance to glyphosate also triggers enhanced fitness in a glyphosate-free environment [30-34].

However, EFSA [93] did not request data on relevant parameters for judging a plant's fitness such as seed dormancy, duration of flowering, number of pollen or viability of pollen. Significant differences that were observed at the time of first flowering, seed maturity and lodging, were set aside by EFSA; they were not considered to be biologically relevant and therefore did not undergo any further assessment. In conclusion, there was no targeted approach to assess fitness, persistence or invasiveness of oilseed rape MON88302.

Furthermore, and to pursue the aspects presented above, EFSA [93] only took into account the characteristics observed in the original event. By assuming that offspring and hybrids would show the same characteristics as the original events, EFSA did not consider publications that indicate unexpected changes in the fitness of transgenic plants unrelated to the intended trait $[56,57]$. Contrary to what, for example, was found necessary by Huang et al. [27] in the case of rice, EFSA did not request any experimental data from any spontaneous offspring or potential hybrids. No crossing experiments with MON88302 were performed to investigate the effects of the transgenes in plants with other genetic backgrounds.

More generally, the staged approach as suggested by EFSA [7] might fail to produce sufficiently robust and reliable results, because
1. the potential impacts caused by the offspring of the GE plants are mostly assessed at the level of the original event,

2. in terms of potential hazards, only changes in fitness that exacerbate weed problems, displacement or potential extinction of native plant species are taken into account.

As a result, there are considerable gaps in EFSA risk assessment: if GE plants and/or their altered genetic material are able to persist in the environment and to introgress domesticated or wild relatives, then risks emerging from genome $\times$ environment interactions or from crossing/hybridisation are very likely to escape the process of ERA. This process fails to address the real dimension of spatio-temporal complexity connected with releases of GE plants that can persist and propagate in the environment.

We conclude that there are some fundamental problems with the ERA of GE plants that can persist and spontaneously propagate in the environment, especially if gene flow to wild relatives cannot be excluded. If the spatio-temporal dimension cannot be determined, problem formulation by EFSA [7], including hazard identification, hazard characterisation and exposure characterisation, might not be sufficiently defined to conclude on the environmental risks. To address the spatio-temporal dimension sufficiently, the following questions should be answered (Table 4):

- Can genetic stability be controlled in following generations?

- How can genetic diversity in the wild population of the same species be taken into account?

- Will there be gene flow to other species?

- How can the population dynamics and life cycle aspects of the wild species be integrated?

- Can the receiving environment be defined in regard to relevant interactions and confined in regard to potential spread?

While genetic stability over several generations might be demonstrated in domesticated varieties under normal field conditions or in the greenhouse, genome $\times$ environmental interactions and introgression into heterogeneous genetic backgrounds can still trigger unpredictable next generation effects. Adverse effects can emerge from interaction with closer (associated microbiomes) or wider environments (such as food webs, predators, beneficial organisms). Complex biological interactions (e.g. crosstalk between signalling pathways) have to be taken into account. 
Table 4 Some specific issues relevant for the assessment of 'spatio-temporal controllability' (vertical reading)

\begin{tabular}{|c|c|c|}
\hline Biology of the species (wild type) & $\begin{array}{l}\text { Interactions of the organisms } \\
\text { with the environment (wild type) }\end{array}$ & $\begin{array}{l}\text { The intended biological characteristics } \\
\text { of the GE organism }\end{array}$ \\
\hline Potential to persist and propagate & $\begin{array}{l}\text { Interactions within the ecosystem: } \\
\text { Position in the food web } \\
\text { Closely associated organisms (microbiome, } \\
\text { symbiotic organisms) } \\
\text { Within the wider environment (such as } \\
\text { beneficial/antagonist insects, soil organisms, } \\
\text { protected/endangered species) }\end{array}$ & $\begin{array}{l}\text { How can genetic stability be controlled in fol- } \\
\text { lowing generations after the release? }\end{array}$ \\
\hline Population dynamics and life cycle & $\begin{array}{l}\text { Impact of biotic stressors e.g. pests and patho- } \\
\text { gens }\end{array}$ & $\begin{array}{l}\text { Does the GE trait impact the fitness of the } \\
\text { organisms? }\end{array}$ \\
\hline $\begin{array}{l}\text { Potential to spread beyond fields/into different } \\
\text { ecosystems }\end{array}$ & $\begin{array}{l}\text { Occurrence of abiotic stressors such as climate } \\
\text { conditions (in regard to the whole life cycle) }\end{array}$ & $\begin{array}{l}\text { Does the trait impact the composition of bio- } \\
\text { logically active compounds? }\end{array}$ \\
\hline $\begin{array}{l}\text { Potential for reproduction with wild populations } \\
\text { of the same species }\end{array}$ & Role and function in energy- and nutrient-cycle & $\begin{array}{l}\text { Can the persistence of the organisms be deter- } \\
\text { mined if necessary? }\end{array}$ \\
\hline \multicolumn{3}{|l|}{$\begin{array}{l}\text { Genetic diversity in wild populations of the same } \\
\text { species }\end{array}$} \\
\hline Potential for gene flow to other species & & \\
\hline
\end{tabular}

Whatever the case, the biological characteristics of the original events alone cannot be regarded as sufficient to predict all relevant effects that can emerge in the next generations, and from interactions with the receiving environments. More generally, if the spatiotemporal dimension for a given GE crop utilisation cannot be defined, risk assessment of GE organisms has to consider evolutionary dimensions. The problem: evolutionary dynamics combine large numbers of individuals on the population level and singularities on the molecular scale. Thus, evolutionary processes make it possible to turn events with a low probability of ever happening into events that may feasibly happen [95]. Under these conditions, for example, the fitness of new genomic constituents cannot be calculated in absolute terms; it will depend on the environment and future changes.

\section{'Spatio-temporal controllability' as cut-off criteria in ERA of GE plants}

Risk assessors and risk managers need to solve the problems of how to come to robust conclusions and make reliable decisions that take high levels of spatio-temporal complexity also in other areas of regulation. For example, EU Regulation for Registration, Evaluation, Authorisation and Restriction of Chemicals (REACH) (Regulation (EC) No 1907/2006 [96]) and pesticides (Regulation (EC) No 1107/2009 [97]) deal with similar problems. The spatio-temporal dimension also plays a decisive role in this context. For example, Recital 76 of the REACH Regulation [96] addresses the issue: "Experience at international level shows that substances with characteristics rendering them persistent, likely to bioaccumulate and toxic, or very persistent and very likely to bioaccumulate, present a very high concern, while criteria have been developed allowing the identification of such substances." Consequently, criteria to identify persistent, bio-accumulative and toxic, as well as very persistent and very bio-accumulative chemical substances, are defined in ANNEX XIII of the EU Regulation (EC) No 1907/2006 [96].

Further, EU Regulation (EC) No 1107/2009 (pesticide regulation) [97] integrates the criteria of POP (persistent organic pollutant), PBT (persistent, bio-accumulative, toxic) and $\mathrm{vPvB}$ (very persistent, very bio-accumulative) into the regulatory decision-making process. These criteria function as so-called cut-off criteria: in essence, the approval process should not proceed if the substance is "POP", "PBT" or "vPvB". In this context, it is important that the chemical substances are not only assessed in regard to their toxicity but also, more generally, in regard to their "fate and behaviour in the environment" (EU Pesticide Regulation (EC) No 1107/2009, Annex II, 3.7. [97]) which gives decisive weight to the spatiotemporal dimension: if a substance is regarded as very persistent and very bio-accumulative, there might still be some uncertainty or non-knowledge in regard to its actual long-term adverse effects. Nevertheless, according to the pesticide Regulation [97], it cannot be approved. For example, Annex II, point 3.7.3 reads: "An active substance, safener or synergist shall only be approved if it is not considered to be a very persistent and very bioaccumulative substance $(v P v B)$ " [97].

The way in which cut-off criteria were established for chemicals could also be useful as a model for the risk assessment of GE organisms. Despite there being many differences between the ERA of chemicals and GE organisms, in both cases long-term effects (spatio-temporal 
complexity) play a decisive role in decision-making. Therefore, similarly to EU regulation of chemicals, the fate and behaviour of the organisms in the environment should be a crucial aspect in the ERA of GE organisms. Persistence can be self-sustaining, or be dependent on gene flow from cultivation, or spillage of GE plants. If volunteer generations may occur and/or if gene flow to wild relatives has to be expected, the biological characteristics of the next generation might substantially deviate from the original event in regard to fitness, composition and or environmental interaction and risk assessment will substantially suffer from major uncertainties. Therefore, if it were known that GE organisms could escape 'spatiotemporal controllability' by reproducing within natural populations without any effective control of spread or persistence, then the authorisation process cannot proceed and the application for the release of the GE organisms has to be rejected.

How then can criteria be developed for the risk assessment of GE organisms that are sufficiently well defined and applicable in the approval process, as well as take into account uncertainties and limits of current knowledge? As described above in the context of chemical substances, the cut-off criteria are defined so that known characteristics of the substances are used to integrate uncertainties around actual long-term impacts into decision-making.

In close analogy, the criteria applied in the risk assessment of GE organisms should be as clear and well defined. We propose using well-established scientific criteria from three areas of knowledge to take into consideration: (1) the (natural) biology of the organisms (2) their (naturally) occurring interactions with the environment (biotic and abiotic) and (3) the intended biological characteristics (traits) inserted through genetic engineering. These three layers of criteria could be combined to establish an extra step in the risk assessment of GE organisms aimed at assessing 'spatio-temporal controllability'. Table 4 provides an overview of some relevant details that can be used to evaluate 'spatio-temporal controllability' in this context.

This approach uses specific 'knowns' to decide upon 'known unknowns' (e.g. next generation effects and genomic $x$ environmental interactions). It is assumed, the criterion of 'spatio-temporal controllability' can inform regulatory decision-making even in the light of major uncertainties emerging from the spatio-temporal dimension. This can be seen as the equivalent of cut-off criteria such as "PBT" and "vPvB" that are anchored in the EU REACH Regulation [96]).

The assessment of 'spatio-temporal controllability' as suggested is not an assessment of specific risk per se. Rather, it is related to the overall conclusiveness of the risk assessment. If 'spatio-temporal controllability' cannot be demonstrated, the risk assessment cannot proceed and the application for the release of the GE organism has to be rejected. There are already several examples of inconclusive EFSA opinions that stopped or substantially delayed the approval process e.g. EFSA opinions on maize 98140 [98] and maize 3272 [99]. Furthermore, in an EFSA presentation from 2018 [100], the following reasons were given for rendering scientific opinions of EFSA inconclusive: (i) Lack of sufficient data to conclude the risk assessment (e.g.) (ii) Lack of toxicological study (iii) Incomplete set of data linked to genotoxicity (iv) Lack of complete set of compositional data (v) data to characterise the process/the product (vi) Lack of data on efficacy (vii) Waiving of data and (viii) Inadequate study design.

To integrate 'spatio-temporal controllability' in ERA, EFSA guidance [7] should be revised and amended to address the issue of next generation effects more thoroughly and comprehensively. More specifically, future guidance should give more weight to persistence, selfpropagation of GE plants and potential gene flow to wild relatives, even in cases where the original event does not enhance fitness or invasiveness. Consequently, EFSA should explicitly address the criteria of 'spatio-temporal controllability' and indicate the resulting uncertainties and the potential consequences for the conclusiveness of the overall opinion.

Our recommendation is backed by EU GMO Directive [2].

According to Krämer [101], spatio-temporal control is a necessary prerequisite to enable the precautionary principle. Directive 2001/18/EC [2] foresees the possible withdrawal of authorisation in case of urgency (Article 23) or the rejection of renewal of the authorisation after ten years (Article 17). Therefore, Krämer comes to the conclusion that "Where there is, in a concrete case, a likelihood that genetically modified plants or animals cannot be retrieved, the legal obligation to ensure that any release must be 'safe' requires the refusal to authorize such releases." (paragraph 250 ).

\section{Conclusions}

GE plants did not undergo evolutionary processes, and they do not derive from existing biodiversity. Therefore, their introduction into the environment, large-scale cultivation and products derived thereof in the food and feed chain expose humans and the environment to unprecedented risks. We show that the risk assessment of GE plants that can persist and propagate in the environment cannot be reduced to the specific traits and characteristics known at the stage of application; it also has to take into account effects that can emerge after a number of generations, in other genetic backgrounds or under 
specific stress conditions. Furthermore, we show that the exacerbation of the weed problems and the displacement or even extinction of native plant species as taken into account by ERA of EFSA are not the only risks that might arise from persistence and self-propagation of GE crops. Much more weight has to be given to the assessment of plant interactions and biological communication networks, such as within the food web, the soil organisms or insects, e.g. pollinators and other interacting organisms that might be disturbed or disrupted. Very generally, in the light of these uncertainties and research gaps, it has to be concluded that at some point, the uncertainties and unknowns in risk assessment will become predominant in comparison to the knowledge available, affecting the ability to conclude on the safety of GE plants. Consequently, robust and sufficiently reliable risk assessment of GE organisms can only be conducted if it is based on a spatio-temporal dimension that is clearly confined.

Against this backdrop, we recommend establishing 'cut-off criteria' in risk assessment that take the factual limits of knowledge into account. It is proposed to introduce these 'cut-off criteria', based on an additional step of 'spatio-temporal controllability' within risk assessment. This new step combines three areas:

1. the natural biology of the organisms,

2. their naturally occurring interactions with the environment (biotic and abiotic),

3. the intended biological characteristics of the GE organism.

The combination of these three layers in one specific, additional step in risk assessment has the advantage that they are already being used to some extent in current EFSA risk assessment; many of the details to assess these areas are very well known. If it is known that GE organisms can escape 'spatio-temporal controllability' because they can propagate within natural populations with no effective control of spread or persistence, then the authorisation process cannot proceed and the release of the GE organism cannot be allowed. This concept can be used to delineate some of the boundaries between known and unknowns considered to be crucial. Consequently, this additional step in risk assessment will foster the robustness of risk assessment and can substantially benefit the reliability of decision-making within approval processes.

The cut-off criteria should not only be applied to applications for commercial cultivation but also to imports that are likely to cause spillage of viable kernels from the relevant events/species. In general, the release of GE plants should not be allowed if their persistence in the environment cannot be controlled in the spatio-temporal dimension. This finding is especially relevant in regard to projects and applications that aim to deliberately release GE organisms into natural populations.

\section{Abbreviations}

Bt: Bacillus thuringiensis; GE: Genetically engineered; GMOs: Genetically modified organisms; EFSA: European food safety authority; EPSPS: 5-enolpyruvylshikimate-3-phosphate synthase; ERA: Environmental Risk Assessment; PBT: Persistent, bio-accumulative, toxic; POP: Persistent organic pollutant; REACH: Registration, evaluation, authorisation and restriction of chemicals; vPvB: Very persistent, very bio-accumulative.

\section{Acknowledgements \\ The authors especially would like to thank the Mercator Foundation Switzerland.}

\section{Authors' contributions}

$\mathrm{CT}$ drafted and wrote the manuscript. $\mathrm{KK}, \mathrm{AB}$ and JM contributed to the draft and provided feedback to the manuscript. All authors read and approved the final manuscript.

\section{Funding}

The project conducted for the publication was funded by the Mercator Foundation Switzerland (2016-0083). Additional funding from Testbiotech (www.testbiotech.org). Katharina Kawall works for the Fachstelle Gentechnik und Umwelt which is funded by the German Federal Ministry of Environment (https://fachstelle-gentechnik-umwelt.de/).

Availability of data and materials

Not applicable.

Ethics approval and consent to participate

Not applicable.

\section{Consent for publication}

Not applicable.

\section{Competing interests}

The authors declare that they have no competing interests.

\section{Author details}

${ }^{1}$ Testbiotech e.V, Institute for Independent Impact Assessment of Biotechnology, Frohschammerstr. 14, 80807 Munich, Germany. ${ }^{2}$ Fachstelle Gentechnik und Umwelt, Frohschammerstr. 14, 80807 Munich, Germany.

Received: 18 August 2019 Accepted: 3 February 2020

Published online: 27 February 2020

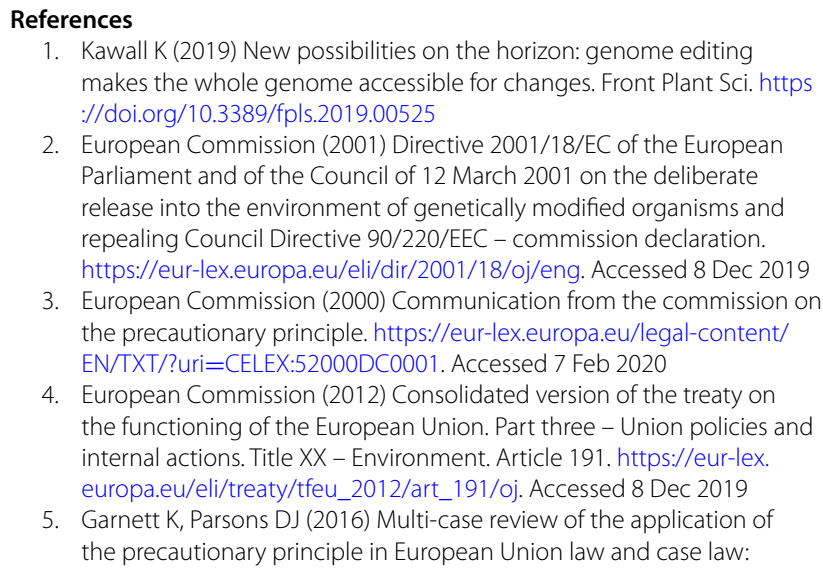


application of the precautionary principle. Risk Anal 37:502-516. https ://doi.org/10.1111/risa.12633

6. Fisher EC, Jones JS, von Schomberg R (eds) (2006) Implementing the precautionary principle: perspectives and prospects. Edward Elgar Publishing, Cheltenham

7. EFSA (2010) Guidance on the environmental risk assessment of genetically modified plants: EFSA guidance document on the ERA of GM plants. EFSA J 8(11):1879. https://doi.org/10.2903/j.efsa.2010.1879

8. Dobzhansky TG (1964) Heredity and the nature of man. Harcourt, Brace \&World, New York

9. Bhatnagar-Mathur P, Vadez V, Sharma KK (2008) Transgenic approaches for abiotic stress tolerance in plants: retrospect and prospects. Plant Cell Rep 27(3):411-424. https://doi.org/10.1007/s00299-007-0474-9

10. Cabello JV, Lodeyro AF, Zurbriggen MD (2014) Novel perspectives for the engineering of abiotic stress tolerance in plants. Curr Opin Biotechnol 26:62-70. https://doi.org/10.1016/j.copbio.2013.09.011

11. Khan MS, Khan MA, Ahmad D (2016) Assessing utilization and environmental risks of important genes in plant abiotic stress tolerance. Front Plant Sci 7:792. https://doi.org/10.3389/fpls.2016.00792

12. Castiglioni P, Warner D, Bensen RJ, Anstrom DC, Harrison J, Stoecker M, Abad M, Kumar G, Salvador S, D'Ordine R, Navarro S, Back S, Fernandes M, Targolli J, Dasgupta S, Bonin C, Luethy MH, Heard JE (2008) Bacterial RNA chaperones confer abiotic stress tolerance in plants and improved grain yield in maize under water-limited conditions. Plant Physiol 147(2):446-455. https://doi.org/10.1104/pp.108.118828

13. McFadden J, Smith D, Wechsler S, Wallander S (2019) Development, adoption, and management of drought-tolerant corn in the United States. Economic Research Service, Economic Information Bulletin Number 204. https://ageconsearch.umn.edu/record/288289. Accessed 8 Dec 2019

14. Londo JP, Bollman MA, Sagers CL, Lee EH, Watrud LS (2011) Changes in fitness-associated traits due to the stacking of transgenic glyphosate resistance and insect resistance in Brassica napus L. Heredity 107(4):328-337. https://doi.org/10.1038/hdy.2011.19

15. Londo JP, Bollman MA, Sagers CL, Lee EH, Watrud LS (2011) Glyphosatedrift but not herbivory alters the rate of transgene flow from single and stacked trait transgenic canola (Brassica napus) to nontransgenic $B$. napus and B. rapa. New Phytol 191(3):840-849. https://doi.org/10.111 1/j.1469-8137.2011.03706.x

16. Zhang L, Hou D, Chen X, Li D, Zhu L, Zhang Y, Li J, Bian Z, Liang X, Cai $X$, Yin Y, Wang C, Zhang T, Zhu D, Zhang D, Xu J, Chen Q, Ba Y, Liu J, Wang Q, Chen J, Wang J, Wang M, Zhang Q, Zhang J, Zen K, Zhang C-Y (2012) Exogenous plant MIR168a specifically targets mammalian LDLRAP1: evidence of cross-kingdom regulation by microRNA. Cell Res 22(1):107-126. https://doi.org/10.1038/cr.2011.158

17. Lu B-R, Yang C (2009) Gene flow from genetically modified rice to its wild relatives: assessing potential ecological consequences. Biotechnol Adv 27(6):1083-1091. https://doi.org/10.1016/j.biotechadv.2009.05.018

18. Letourneau DK, Hagen JA (2012) Plant fitness assessment for wild relatives of insect resistant Bt-crops. J Bot 2012:389247. https://doi. org/10.1155/2012/389247

19. Meier MS, Trtikova M, Suter M, Edwards PJ, Hilbeck A (2013) Simulating evolutionary responses of an introgressed insect resistance trait for ecological effect assessment of transgene flow: a model for supporting informed decision-making in environmental risk assessment. Ecol Evol 3(2):416-423. https://doi.org/10.1002/ece3.463

20. Mason KL, Stepien TA, Blum JE, Holt JF, Labbe NH, Rush JS, Raffa KF, Handelsman J (2011) From commensal to pathogen: translocation of Enterococcus faecalis from the midgut to the hemocoel of Manduca sexta. Mbio 2(3):e00065-11. https://doi.org/10.1128/mbio.00065-11

21. Mason P, Braun L, Warwick SI, Zhu B (2003) Transgenic Bt-producing Brassica napus: Plutella xylostella selection pressure and fitness of weedy relatives. Environ Biosafety Res 2(4):263-276. https://doi.org/10.1051/ ebr:2003016

22. Aono M, Wakiyama S, Nagatsu M, Nakajima N, Tamaoki M, Kubo A, Saji H (2006) Detection of feral transgenic oilseed rape with multipleherbicide resistance in Japan. Environ Biosafety Res 5(2):77-87. https:// doi.org/10.1051/ebr:2006017

23. Hjältén J, Axelsson EP, Whitham TG, LeRoy CJ, Julkunen-Tiitto R, Wennström A, Pilate G (2012) Increased resistance of Bt Aspens to Phratora vitellinae (Coleoptera) leads to increased plant growth under experimental conditions. PLoS ONE 7(1):e30640. https://doi. org/10.1371/journal.pone.0030640

24. Laughlin KD, Power AG, Snow AA, Spencer LJ (2009) Risk assessment of genetically engineered crops: fitness effects of virus-resistance transgenes in wild Cucurbita pepo. Ecol Appl 19(5):1091-1101. https:// doi.org/10.1890/08-0105.1

25. Snow AA, Uthus KL, Culley TM (2001) Fitness of hybrids between weedy and cultivated radish: implications for weed evolution. Ecol Appl 11(3):934-943. https://doi.org/10.1890/1051-0761(2001)011\%5b093 4:FOHBWA\%5d2.0.CO;2

26. Ellstrand NC, Meirmans P, Rong J, Bartsch D, Ghosh A, de Jong TJ, Haccou P, Lu BL, Snow AA, Stewart N Jr, Strasburg JL, Van Tienderen PH, Vrieling K, Hooftman D (2013) Introgression of crop alleles into wild or weedy populations. Annu Rev Ecol Evol Syst 44:325-345. https://doi. org/10.1146/annurev-ecolsys-110512-135840

27. Huang Y, Wang Y, Qiang S, Song X, Dai W (2019) Fitness of F1 hybrids between stacked transgenic rice T1 C-19 with cry $1 C^{*} /$ bar genes and weedy rice. J Integr Agric 18(12):2793-2805. https://doi.org/10.1016/ S2095-3119(19)62662-6

28. Bollinedi H, Gopala Krishnan S, Prabhu KV, Singh NK, Mishra S, Khurana JP, Singh AK (2017) Molecular and functional characterization of GR2-R1 event based backcross derived lines of golden rice in the genetic background of a mega rice variety Swarna. PLoS ONE 12(1):e0169600. https ://doi.org/10.1371/journal.pone.0169600

29. Wilson, A (2018) Goodbye to golden rice? GM trait leads to drastic yield loss and "metabolic meltdown". Bioscience resource project. https:// bioscienceresource.org/goodbye-to-golden-rice-gm-trait-leads-todrastic-yield-loss-and-metabolic-meltdown/. Accessed 8 Dec 2019

30. Fang J, Nan P, Gu Z, Ge X, Feng Y-Q, Lu B-R (2018) Overexpressing exogenous 5-enolpyruvylshikimate-3-phosphate synthase (EPSPS) genes increases fecundity and auxin content of transgenic arabidopsis plants. Front Plant Sci 9:233. https://doi.org/10.3389/fpls.2018.00233

31. Beres ZT (2019) Ecological and evolutionary implications of glyphosate resistance in Conyza canadensis and Arabidopsis thaliana. Dissertation presented in partial fulfillment of the requirements for the degree Doctor of Philosophy in the graduate school of the Ohio State University. http://rave.ohiolink.edu/etdc/view?acc_num=osu1555600547328876. Accessed 7 Feb 2020

32. Beres ZT, Yang X, Jin L, Zhao W, Mackey DM, Snow AA (2018) Overexpression of a native gene encoding 5-enolpyruvylshikimate-3-phosphate synthase (EPSPS) may enhance Fecundity in Arabidopsis thaliana in the absence of glyphosate. Int J Plant Sci 179(5):390-401. https://doi. org/10.1086/696701

33. Wang W, Xia H, Yang X, Xu T, Si HJ, Cai XX, Wang F, Su J, Snow AA, Lu B-R (2014) A novel 5-enolpyruvoylshikimate-3-phosphate (EPSP) synthase transgene for glyphosate resistance stimulates growth and fecundity in weedy rice (Oryza sativa) without herbicide. New Phytol 202(2):679688. https://doi.org/10.1111/nph.12428

34. Yang X, Li L, Jiang X, Wang W, Cai X, Su J, Wang F, Lu B-R (2017) Genetically engineered rice endogenous 5-enolpyruvoylshikimate-3-phosphate synthase (epsps) transgene alters phenology and fitness of crop-wild hybrid offspring. Sci Rep 7(1):6834. https://doi.org/10.1038/ s41598-017-07089-9

35. Vila-Aiub MM, Neve P, Powles SB (2009) Fitness costs associated with evolved herbicide resistance alleles in plants. New Phytol 184(4):751767. https://doi.org/10.1111/j.1469-8137.2009.03055.x

36. Vila-Aiub M, Yu Q, Powles S (2019) Do plants pay a fitness cost to be resistant to glyphosate? New Phytol 223(2):532-547. https://doi. org/10.1111/nph.15733

37. Vila-Aiub MM, Goh SS, Gaines TA, Han H, Busi R, Yu Q, Powles SB (2014) No fitness cost of glyphosate resistance endowed by massive EPSPS gene amplification in Amaranthus palmeri. Planta 239(4):793-801. https ://doi.org/10.1007/s00425-013-2022-x

38. Han H, Vila-Aiub MM, Jalaludin A, Yu Q, Powles SB (2017) A double EPSPS gene mutation endowing glyphosate resistance shows a remarkably high resistance cost. Plant, Cell Environ 40(12):3031-3042. https:// doi.org/10.1111/pce.13067

39. Monsanto (2004) WO 2004053055, Transgenic maize with enhanced phenotype. https://worldwide.espacenet.com/publicationDetails/bibli $\mathrm{0} ? \|=1 \& \mathrm{ND}=3 \&$ adjacent $=$ true\&locale $=$ en_EP\&FT $=$ D\&date $=20040$ 624\&CC $=$ WO\&NR=2004053055A2\&KC =A2\#. Accessed 7 Feb 2020 
40. Vigueira CC, Li W, Olsen KM (2013) The role of Bh4 in parallel evolution of hull colour in domesticated and weedy rice. J Evol Biol 26(8):1738-1749. https://doi.org/10.1111/jeb.12171

41. Kanapeckas KL, Vigueira CC, Ortiz A, Gettler KA, Burgos NR, Fischer AJ, Lawton-Rauh AL (2016) Escape to ferality: the endoferal origin of weedy rice from crop rice through de-domestication. PLOS ONE 11(9):e0162676. https://doi.org/10.1371/journal.pone.0162676

42. Chen LJ, Lee DS, Song ZP, Suh HS, Lu B-R (2004) Gene flow from cultivated rice (Oryza sativa) to its weedy and wild relatives. Ann Bot 93(1):67-73. https://doi.org/10.1093/aob/mch006

43. Lu B-R, Snow AA (2005) Gene flow from genetically modified rice and its environmental consequences. BioScience 55(8):669-678. https:// doi.org/10.1641/0006-3568(2005)055[0669:GFFGMR]2.0.CO;2

44. Cao Q-J, Xia H, Yang X, Lu B-R (2009) Performance of hybrids between weedy rice and insect-resistant transgenic rice under field experiments: implication for environmental biosafety assessment. J Integr Plant Biol 51(12):1138-1148. https://doi.org/10.111 1/j.1744-7909.2009.00877.x

45. Yang C, Wang Z, Yang X, Lu B-R (2014) Segregation distortion affected by transgenes in early generations of rice crop-weed hybrid progeny: implications for assessing potential evolutionary impacts from transgene flow into wild relatives. J Syst Evol 52(4):466-476. https:// doi.org/10.1111/jse.12078

46. Xia $\mathrm{H}$, Zhang $\mathrm{H}$, Wang $\mathrm{W}$, Yang $\mathrm{X}$, Wang $F$, Su J, Xia H, Xu K, Cai $X$, Lu B-R (2016) Ambient insect pressure and recipient genotypes determine fecundity of transgenic crop-weed rice hybrid progeny: implications for environmental biosafety assessment. Evol Appl 9(7):847-856. https://doi.org/10.1111/eva.12369

47. Yang X, Li L, Cai X, Wang F, Su J, Lu B-R (2015) Efficacy of insectresistance $\mathrm{Bt} / \mathrm{CpTI}$ transgenes in F5-F7 generations of rice crop-weed hybrid progeny: implications for assessing ecological impact of transgene flow. Sci Bull 60(18):1563-1571. https://doi.org/10.1007/ s11434-015-0885-x

48. Zhang J, Kang Y, Valverde BE, Dai W, Song X, Qiang S (2018) Feral rice from introgression of weedy rice genes into transgenic herbicideresistant hybrid-rice progeny. J Exp Bot 69(16):3855-3865. https://doi. org/10.1093/jxb/ery210

49. Bauer-Panskus A, Breckling B, Hamberger S, Then C (2013) Cultivation-independent establishment of genetically engineered plants in natural populations: current evidence and implications for EU regulation. Environ Sci Eur 25(1):34. https://doi. org/10.1186/2190-4715-25-34

50. Pandolfo CE, Presotto A, Carbonell FT, Ureta S, Poverene M, Cantamutto M (2018) Transgene escape and persistence in an agroecosystem: the case of glyphosate-resistant Brassica rapa L. in central Argentina. Environ Sci Pollut Res 25(7):6251-6264. https://doi.org/10.1007/s1135 6-017-0726-3

51. Schulze J, Frauenknecht T, Brodmann P, Bagutti C (2014) Unexpected diversity of feral genetically modified oilseed rape (Brassica napus L.) despite a cultivation and import ban in Switzerland. PLOS ONE 9(12):e114477. https://doi.org/10.1371/journal.pone.0114477

52. Mizuguti A, Yoshimura Y, Shibaike H, Matsuo K (2011) Persistence of feral populations of Brassica napus originated from spilled seeds around the Kashima seaport in Japan. Jpn Agric Res Q 45(2):181-185. https://doi. org/10.6090/jarq.45.181

53. Katsuta K, Matsuo K, Yoshimura Y, Ohsawa R (2015) Long-term monitoring of feral genetically modified herbicide-tolerant Brassica napus populations around unloading Japanese ports. Breed Sci 65(3):265-275. https://doi.org/10.1270/jsbbs.65.265

54. Warwick SI, Légère A, Simard M-J, James T (2008) Do escaped transgenes persist in nature? The case of an herbicide resistance transgene in a weedy Brassica rapa population. Mol Ecol 17(5):13871395. https://doi.org/10.1111/j.1365-294x.2007.03567.x

55. Knispel AL, McLachlan SM (2010) Landscape-scale distribution and persistence of genetically modified oilseed rape (Brassica napus) in Manitoba, Canada. Environ Sci Pollut Res 17(1):13-25. https://doi. org/10.1007/s11356-009-0219-0

56. Vacher C, Weis AE, Hermann D, Kossler T, Young C, Hochberg ME (2004) Impact of ecological factors on the initial invasion of Bt transgenes into wild populations of birdseed rape (Brassica rapa). Theor Appl Genet 109(4):806-814. https://doi.org/10.1007/s00122-004-1696-7
57. Kawata M, Murakami K, Ishikawa T (2009) Dispersal and persistence of genetically modified oilseed rape around Japanese harbors. Environ Sci Pollut Res 16(2):120-126. https://doi.org/10.1007/s11356-008-0074-4

58. Matthews D, Jones H, Gans P, Coates S, Smith LMJ (2005) Toxic secondary metabolite production in genetically modified potatoes in response to stress. J Agric Food Chem 53(20):7766-7776. https://doi.org/10.1021/ jf050589r

59. Meyer P, Linn F, Heidmann I, Meyer H, Niedenhof I, Saedler H (1992) Endogenous and environmental factors influence $35 \mathrm{~S}$ promoter methylation of a maize A1 gene construct in transgenic petunia and its colour phenotype. Mol Gen Genet MGG 231(3):345-352. https://doi. org/10.1007/bf00292701

60. Then C, Lorch A (2008) A simple question in a complex environment: How much Bt toxin do genetically engineered MON810 maize plants actually produce? In: Implications of GM-Crop cultivation at large spatial scales. Edited by: Breckling B, Verhoeven R. Theorie in der Ökologie, Band 14. Peter Lang, Frankfurt, pp 17-21

61. Trtikova M, Wikmark OG, Zemp N, Widmer A, Hilbeck A (2015) Transgene expression and Bt protein content in transgenic Bt maize (MON810) under optimal and stressful environmental conditions. PLoS ONE 10(4):e0123011. https://doi.org/10.1371/journal.pone.0123011

62. Zeller SL, Kalinina O, Brunner S, Keller B, Schmid B (2010) Transgene $x$ environment interactions in genetically modified wheat. PLoS ONE 5(7):e11405. https://doi.org/10.1371/journal.pone.0011405

63. Zhu X, Sun L, Kuppu S, Hu R, Mishra N, Smith J, Esmaeili N, Herath M, Gore MA, Payton P, Shen G, Zhang H (2018) The yield difference between wild-type cotton and transgenic cotton that expresses IPT depends on when water-deficit stress is applied. Sci Rep 8(1):2538. https://doi.org/10.1038/s41598-018-20944-7

64. Agapito-Tenfen SZ, Guerra MP, Wikmark O-G, Nodari RO (2013) Comparative proteomic analysis of genetically modified maize grown under different agroecosystems conditions in Brazil. Proteome Sci 11(1):46. https://doi.org/10.1186/1477-5956-11-46

65. Adamczyk JJ, Meredith WR (2004) Genetic basis for variability of Cry1Ac expression among commercial transgenic Bacillus thuringiensis (Bt) cotton cultivars in the United States. J Cotton Sci 8(1):433. https://pubag .nal.usda.gov/catalog/10670

66. Adamczyk JJ, Perera O, Meredith WR (2009) Production of mRNA from the cry 1 Ac transgene differs among Bollgard ${ }^{\circledR}$ lines which correlates to the level of subsequent protein. Transgenic Res 18(1):143-149. https:// doi.org/10.1007/s11248-008-9198-z

67. Beura K, Rakshit A (2013) Bt cotton influencing enzymatic activities under varied soils. Open J Ecol 3(8):505-509. https://doi.org/10.4236/ oje.2013.38059

68. Chen Y, Tian J-C, Wang W, Fang Q, Akhtar ZR, Peng Y-F, Cui H, Guo Y-Y, Song Q-S, Ye G-Y (2012) Bt rice expressing Cry1Ab does not stimulate an outbreak of its non-target herbivore. Nilaparvata lugens. Transgenic Res 21(2):279-291. https://doi.org/10.1007/s11248-011-9530-x

69. Luo Z, Dong H, Li W, Ming Z, Zhu Y (2008) Individual and combined effects of salinity and waterlogging on Cry1Ac expression and insecticidal efficacy of Bt cotton. Crop Prot 27(12):1485-1490. https://doi. org/10.1016/j.cropro.2008.06.006

70. Wang J, Chen Y, Yao M, Li Y, Wen Y, Chen Y, Zhang X, Chen D (2015) The effects of high temperature level on square Bt protein concentration of Bt cotton. J Integr Agric 14(10):1971-1979. https://doi.org/10.1016/ s2095-3119(15)61049-8

71. Jenczewski E, Ronfort J, Chèvre A-M (2003) Crop-to-wild gene flow, introgression and possible fitness effects of transgenes. Environ Biosafety Res 2(1):9-24. https://doi.org/10.1051/ebr:2003001

72. Wegier A, Piñeyro-Nelson A, Alarcón J, Gálvez-Mariscal A, Álvarez-Buylla ER, Piñero D (2011) Recent long-distance transgene flow into wild populations conforms to historical patterns of gene flow in cotton (Gossypium hirsutum) at its centre of origin. Mol Ecol 20(19):4182-4194. https://doi.org/10.1111/j.1365-294x.2011.05258.x

73. Hu J, Zhang J, Chen X, Lv J, Jia H, Zhao S, Lu M (2017) An empirical assessment of transgene flow from a Bt transgenic poplar plantation. PLoS ONE 12(1):e0170201. https://doi.org/10.1371/journal.pone.01702 01

74. Saxena D, Flores S, Stotzky G (2002) Bt toxin is released in root exudates from 12 transgenic corn hybrids representing three transformation 
events. Soil Biol Biochem 34(1):133-137. https://doi.org/10.1016/s0038 $-0717(01) 00161-4$

75. Dunfield KE, Germida JJ (2004) Impact of genetically modified crops on soil- and plant-associated microbial communities. J Environ Qual 33(3):806-815

76. Campos RC, Holderbaum DF, Nodari RO, Hernandez MIM (2018) Indirect exposure to Bt maize through pig faeces causes behavioural changes in dung beetles. J Appl Entomol 142(9):893-900. https://doi.org/10.1111/ jen. 12532

77. Seide VE, Bernardes RC, Pereira EJG, Lima MAP (2018) Glyphosate is lethal and Cry toxins alter the development of the stingless bee Melipona quadrifasciata. Environ Pollut 243:1854-1860. https://doi. org/10.1016/j.envpol.2018.10.020

78. Stewart JC, Halfhill MD, Warwick SI (2003) Transgene introgression from genetically modified crops to their wild relatives. Nat Rev Genet 4(10):806-817

79. Andow DA, Zwahlen C (2006) Assessing environmental risks of transgenic plants. Ecol Lett 9(2):196-214. https://doi.org/10.111 $1 / j .1461-0248.2005 .00846 . x$

80. Schaefer HM, Ruxton GD (2011) Plant-animal communication. Oxford University Press, Oxford

81. Choudhary DK, Sharma AK, Agarwal P, Varma A, Tuteja N (2017) Volatiles and food security role of volatiles in agro-ecosystems. Springer, Singapore

82. da Silva KJ, de Armas RD, Soares CRFS, Ogliari JB (2016) Communities of endophytic microorganisms in different developmental stages from a local variety as well as transgenic and conventional isogenic hybrids of maize. World J Microbiol Biotechnol 32:189. https://doi.org/10.1007/ s11274-016-2149-6

83. Wallace JG, Kremling KA, Kovar LL, Buckler ES (2018) Quantitative genetics of the maize leaf microbiome. Phytobiomes J 2(4):208-224. https:// doi.org/10.1094/pbiomes-02-18-0008-r

84. Colombo SM, Campbell LG, Murphy EJ, Martin SL, Arts MT (2018) Potential for novel production of omega-3 long-chain fatty acids by genetically engineered oilseed plants to alter terrestrial ecosystem dynamics. Agric Syst 164:31-37. https://doi.org/10.1016/j.agsy.2018.03.004

85. Agapito-Tenfen SZ, Wickson F (2018) Challenges for transgene detection in landraces and wild relatives: learning from 15 years of debate over GM maize in Mexico. Biodivers Conserv 27(3):539-566. https://doi. org/10.1007/s10531-017-1471-0

86. Trtikova M, Lohn A, Binimelis R, Chapela I, Oehen B, Zemp N, Widmer A, Hilbeck A (2017) Teosinte in Europe - searching for the origin of a novel weed. Sci Rep 7(1):1560. https://doi.org/10.1038/s41598-017-01478-w

87. EFSA (2016) Relevance of new scientific evidence on the occurrence of teosinte in maize fields in Spain and France for previous environmental risk assessment conclusions and risk management recommendations on the cultivation of maize events MON810, Bt11, 1507 and GA21. EFSA Supporting Publications 13(9):1094E. https://doi.org/10.2903/ sp.efsa.2016.en-1094

88. Ellstrand NC (2018) "Born to run"? not necessarily: species and trait bias in persistent free-living transgenic plants. Front Bioeng Biotechnol. https://doi.org/10.3389/fbioe.2018.00088

89. Devos Y, Ortiz-García S, Hokanson KE, Raybould A (2018) Teosinte and maize $\times$ teosinte hybrid plants in Europe-environmental risk assessment and management implications for genetically modified maize. Agric Ecosyst Environ 259(1):19-27. https://doi.org/10.1016/j. agee.2018.02.032

90. Redford KH, Brooks TM, Macfarlane NBW, Adams JS (2019) Genetic frontiers for conservation: an assessment of synthetic biology and biodiversity conservation: technical assessment. IUCN, International Union for Conservation of Nature, IUCN Task Force on Synthetic Biology and Biodiversity Conservation. https://portals.iucn.org/library/node/48408. Accessed 8 Dec 2019
91. Testbiotech (2019) Testbiotech comment on the IUCN report "Genetic frontiers for conservation, an assessment of synthetic biology and biodiversity conservation." https://www.testbiotech.org/content/testb iotech-comment-iucn-report-conservation-synthetic-biology. Accessed 8 Dec 2019

92. Monsanto (2012) Application for authorization to place on the market MON 88302 oilseed rape in the European Union, according to Regulation (EC) No 1829/2003 on genetically modified food and feed, Part VII Summary, Application number EFSA-GMO-BE-2011-101. http:// registerofquestions.efsa.europa.eu/roqFrontend/questionsListLo ader?unit=GMO

93. EFSA (2014) Scientific Opinion on application (EFSA-GMO-BE-2011-101) for the placing on the market of herbicide-tolerant genetically modified oilseed rape MON 88302 for food and feed uses, import and processing under Regulation (EC) No 1829/2003 from Monsanto: scientific Opinion on genetically modified oilseed rape MON 88302. EFSA J 12(6):3701. https://doi.org/10.2903/j.efsa.2014.3701

94. Squire GR, Breckling B, Dietz Pfeilstetter A, Jorgensen RB, Lecomte J, Pivard S, Reuter H, Young MW (2011) Status of feral oilseed rape in Europe: its minor role as a GM impurity and its potential as a reservoir of transgene persistence. Environ Sci Pollut Res 18(1):111-115. https:// doi.org/10.1007/s11356-010-0376-1

95. Breckling B (2013) Transgenic evolution and ecology are proceeding. In: Breckling B, Verhoeven R (eds) GM-crop cultivation - ecological effects on a landscape scale. Theorie in der Ökologie, Band 17. Peter Lang, Frankfurt, pp 130-135

96. European Commission (2006) Regulation (EC) No 1907/2006 of the European Parliament and of the Council of 18 December 2006 concerning the registration, evaluation, authorisation and restriction of chemicals (REACH), establishing a European Chemicals Agency, amending Directive 1999/45/EC and repealing Council Regulation (EEC) No 793/93 and Commission Regulation (EC) No 1488/94 as well as Council Directive 76/769/EEC and Commission Directives 91/155/ EEC, 93/67/EEC, 93/105/EC and 2000/21/EC. https://eur-lex.europa.eu/ eli/reg/2006/1907/oj/eng. Accessed 8 Dec 2019

97. European Commission (2009) Regulation (EC) No 1107/2009 of the European Parliament and of the Council of 21 October 2009 concerning the placing of plant protection products on the market and repealing Council Directives 79/117/EEC and 91/414/EEC. https://eur-lex. europa.eu/eli/reg/2009/1107/oj/eng. Accessed 8 Dec 2019

98. EFSA (2013) Scientific Opinion on application (EFSA-GMO-UK-2008-53) for the placing on the market of herbicide tolerant genetically modified maize 98140 for food and feed uses, import and processing under Regulation (EC) No 1829/2003 from Pioneer Overseas Corporation. EFSA J 11(4):3139. https://doi.org/10.2903/j.efsa.2013.3139

99. EFSA (2013) Scientific Opinion on application (EFSA-GMO-UK-2006-34) for the placing on the market of genetically modified maize 3272 with a thermotolerant alpha-amylase, for food and feed uses, import and processing under Regulation (EC) No 1829/2003 from Syngenta Crop Protection AG. EFSA J 11 (6):3252. https://doi.org/10.2903/j. efsa.2013.3252

100. EFSA (2018) EFSA scientific outputs: Special focus on inconclusive opinions. Presentation delivered by E. Waigmann. https://www.efsa.europ a.eu/sites/default/files/event/180613-p03.pdf. Accessed 8 Dec 2019

101. Krämer $L$ (2013) Genetically modified living organisms and the precautionary principle. https://www.testbiotech.org/content/geneticall y-modified-living-organisms-and-precautionary-principle. Accessed 8 Dec 2019

\section{Publisher's Note}

Springer Nature remains neutral with regard to jurisdictional claims in published maps and institutional affiliations. 